ACCEPTED MANUSCRIPT

\title{
Concurrent ionic migration and electronic effects at the memristive $\mathrm{TiOx} / \mathrm{La} 1 / 3 \mathrm{Ca} / 3 \mathrm{MnO} 3-\mathrm{x}$ interface
}

To cite this article before publication: Wilson Stibens Roman Acevedi et al $2018 \mathrm{~J}$. Phys. D: Appl. Phys. in press https://doi.org/10.1088/1361$\underline{6463 / a a a e d 6}$

\author{
Manuscript version: Accepted Manuscript \\ Accepted Manuscript is "the version of the article accepted for publication including all changes made as a result of the peer review process, \\ and which may also include the addition to the article by IOP Publishing of a header, an article ID, a cover sheet and/or an 'Accepted \\ Manuscript' watermark, but excluding any other editing, typesetting or other changes made by IOP Publishing and/or its licensors" \\ This Accepted Manuscript is @ 2018 IOP Publishing Ltd.
}

During the embargo period (the 12 month period from the publication of the Version of Record of this article), the Accepted Manuscript is fully protected by copyright and cannot be reused or reposted elsewhere.

As the Version of Record of this article is going to be / has been published on a subscription basis, this Accepted Manuscript is available for reuse under a CC BY-NC-ND 3.0 licence after the 12 month embargo period.

After the embargo period, everyone is permitted to use copy and redistribute this article for non-commercial purposes only, provided that they adhere to all the terms of the licence https://creativecommons.org/licences/by-nc-nd/3.0

Although reasonable endeavours have been taken to obtain all necessary permissions from third parties to include their copyrighted content within this article, their full citation and copyright line may not be present in this Accepted Manuscript version. Before using any content from this article, please refer to the Version of Record on IOPscience once published for full citation and copyright details, as permissions will likely be required. All third party content is fully copyright protected, unless specifically stated otherwise in the figure caption in the Version of Record.

View the article online for updates and enhancements. 


\title{
Concurrent ionic migration and electronic effects at the memristive $\mathrm{TiO}_{\mathrm{x}} / \mathrm{La}_{1 / 3} \mathrm{Ca}_{2 / 3} \mathrm{MnO}_{3-\mathrm{x}}$ interface
}

\author{
W. Román Acevedo ${ }^{1,2, *}$, C. Ferreyra ${ }^{1,2, *}$, M.J. Sánchez $^{2,3, \perp}$, C. Acha ${ }^{2,4}$, R. Gay ${ }^{5}$, D. \\ $\operatorname{Rubi}^{1,2,6}$
}

1. GIyA e INN, CNEA, Av. Gral Paz 1499 (1650), San Martín, Buenos Aires, Argentina

2. Consejo Nacional de Investigaciones Científicas y Técnicas (CONICET), Godoy Cruz 2290 (1425), Buenos Aires, Argentina.

3. Centro Atómico Bariloche and Instituto Balseiro, 8400 San Carlos de Bariloche, Río Negro, Argentina

4. Depto. de Física, FCEyN, Universidad de Buenos Aires \& IFIBA-CONICET, Pab. I, Ciudad Universitaria, Buenos

Aires (1428), Argentina

5. CIC nanoGUNE, Tolosa Hiribidea 76, 20018 Donostia-San Sebastián, Spain

6. Escuela de Ciencia y Tecnología, UNSAM, Campus Miguelete (1650), San Martín, Buenos Aires, Argentina

The development of reliable redox-based resistive random-access memory devices requires understanding and disentangling concurrent effects present at memristive interfaces. We report on the fabrication and electrical characterization of $\mathrm{TiO}_{\mathrm{x}} / \mathrm{La}_{1 / 3} \mathrm{Ca}_{2 / 3} \mathrm{MnO}_{3-\mathrm{x}}$ microstructured interfaces and on the modeling of their memristive behavior. We show that a careful tuning of the applied external electrical stimuli allows controlling the redox process between both layers, obtaining multilevel non-volatile resistance states. We simulate the oxygen vacancies dynamics at the interface between both oxides, and successfully reproduce the experimental electrical behavior after the inclusion of an electronic effect, related to the presence of an $n-p$ diode at the interface. The formation of the diode is due to the $n$ - and $p$-character of $\mathrm{TiO}_{\mathrm{x}}$ and $\mathrm{La}_{1 / 3} \mathrm{Ca}_{2 / 3} \mathrm{MnO}_{3-\mathrm{x}}$, respectively. Our analysis indicates that oxygen vacancies migration between both layers is triggered after the diode is polarized either in forward mode or in reverse mode above breakdown. Electrical measurements at different temperatures suggest that the diode can be characterized as Zener-type. The advantages of our junctions for their implementation in RRAM devices are finally discussed.

* These authors contributed equally to this work $\perp$ Corresponding author (MJS), majo@cab.cnea.gov.ar 
Resistance random access memory (ReRAM) devices display a great potential to constitute the new generation of non-volatile memories. These devices are based on the so-called Resistive Switching effect (RS), which consists in the reversible and nonvolatile change of the resistance of metal/insulator/metal stacks upon the application of electrical stress [1,2]. This effect has been ubiquitously found for a number of simple and complex insulating oxides and, in particular, in the case of the celebrated magnetoresistive manganese oxides known as manganites [3]. The RS mechanism in manganite-based devices has been usually related to the electrical field induced drift of oxygen vacancies to and from manganite/metal Schottky interfaces, with the interface resistance modulated by the local concentration of oxygen vacancies [1]. Phenomenological models that reproduce non-trivial features of the experimental observed behavior have been developed [4,5]. Other RS mechanisms such as the formation (and disruption) of a metallic nanofilament bridging both electrodes have been observed for these devices, and in some cases a crossover between both mechanisms has been proposed [6].

Recently it was shown that when oxidizable electrodes such as Ti or/Al are used, a thin oxide layer $\left(\mathrm{TiO}_{\mathrm{x}}\right.$ or $\left.\mathrm{AlO}_{\mathrm{x}}\right)$ is naturally formed at the interface between the metal electrode and the insulating oxide, and the RS behavior is related to a redox process involving the transfer of oxygen ions (vacancies) between both oxide layers [7- 10]. For instance, Herpers et al. conclusively showed by means of hard X-ray photoelectron spectroscopy that bipolar $\mathrm{RS}$ in $\mathrm{Ti} / \mathrm{Pr}_{0.48} \mathrm{Ca}_{0.52} \mathrm{MnO}_{3}$ is related to a redox process between $\mathrm{TiO}_{2} / \mathrm{Pr}_{0.48} \mathrm{Ca}_{0.52} \mathrm{MnO}_{3-\mathrm{x}}$ (high resistance) and $\mathrm{TiO}_{2-\mathrm{y}} / \mathrm{Pr}_{0.48} \mathrm{Ca}_{0.52} \mathrm{MnO}_{3-\mathrm{x}+\mathrm{y}}$ (low resistance) states, where oxygen transfer between both layer follows the application of electrical stimulus [7]. The formation of the $\mathrm{TiO}_{\mathrm{x}}$ layer at the $\mathrm{Ti} / \mathrm{Pr}_{1-\mathrm{x}} \mathrm{Ca}_{\mathrm{x}} \mathrm{MnO}_{3}$ interface and its participation in the memristive mechanism of the interface was determined by transmission electron microscopy by Asanuma et al., for $\mathrm{x}$ ranging from 0 to 1 , indicating a rather general mechanism, independent of the manganite cation stochiometry [8]. Also, Tian et al. [9] showed by transmission electron microscopy and its associated spectroscopic techniques that an insulating $\mathrm{Al}_{\mathrm{x}} \mathrm{O}_{\mathrm{y}}$ layer is formed at the interface between $\mathrm{Al}$ and the metallic niquelate $\mathrm{LaNiO}_{3}$. Again, the observed resistive switching is related to the electrical field driven exchange of oxygen vacancies between $\mathrm{LaNiO}_{3}$ and the interlayer oxide, which drives a redox reaction that forms and dissolves $\mathrm{Al}$ nanoclusters in the $\mathrm{Al}_{\mathrm{x}} \mathrm{O}_{\mathrm{y}}$ insulating matrix. It was also suggested in $\mathrm{Ti} / \mathrm{La}_{0.3} \mathrm{Ca}_{0.7} \mathrm{MnO}_{3} / \mathrm{Si}$ systems that the oxidation and reduction of the $\mathrm{SiO}_{\mathrm{x}}$ layer present at the $\mathrm{La}_{0.3} \mathrm{Ca}_{0.7} \mathrm{MnO}_{3} / \mathrm{Si}$ interface dominates the memristive behavior observed in this system [10]. We notice that the large area of these devices $\left(>30.000 \mu \mathrm{m}^{2}\right)$ favors the migration of $\mathrm{Ti}$ (top electrode material) along extended defects present in the manganite layer until a partial, non-bridging, filament is formed, inhibiting the contribution of the oxidation/reduction of interfacial $\mathrm{TiO}_{\mathrm{x}}$ to the memristive properties of these systems. Impedance spectroscopy experiments support the proposed scenario [10].

In this paper we report on the fabrication of $25 \mu \mathrm{m}^{2} \mathrm{Ti} / \mathrm{La}_{1 / 3} \mathrm{Ca}_{2 / 3} \mathrm{MnO}_{3} / \mathrm{Pt}$ structures and on the study of the dynamics of oxygen vacancies transfer at the $\mathrm{TiO}_{\mathrm{x}} / \mathrm{La}_{1 / 3} \mathrm{Ca}_{2 / 3} \mathrm{MnO}_{3-\mathrm{x}}$ interface. The reduced dimension of these devices in comparison with those reported in Ref. [10] prevents Ti migration along extended defects and allows the redox process at the $\mathrm{TiO}_{\mathrm{x}} / \mathrm{La}_{1 / 3} \mathrm{Ca}_{2 / 3} \mathrm{MnO}_{3 \text {-x }}$ interface to dominate the memristive behavior. The redox process can be controlled-by tuning the voltage excursion during the RESET process (low to high resistance transition) and the compliance current during the SET process 
(high to low transition). In this way we obtain several intermediate resistance levels, appropriate for multilevel devices. We performed numerical simulations by adapting the Voltage Enhanced Oxygen Vacancies drift (VEOV) model, originally developed to explain the resistive switching behavior in single manganites samples [5,6] and further extended for binary oxides $\left(\mathrm{TiO}_{\mathrm{x}}\right)$ based devices [11], to include the mixed $\mathrm{TiO}_{\mathrm{x}} / \mathrm{LCMO}_{3-\mathrm{x}}$ scenario. We show that in addition to oxygen vacancies migration, an electronic effect, related to the existence of an $n-p$ junction at the $\mathrm{TiO}_{\mathrm{x}} / \mathrm{LCMO}_{3-\mathrm{x}}$ interface, should be included in the modeling in order to successfully reproduce the experimental behavior.

Polycristalline $\mathrm{La}_{1 / 3} \mathrm{Ca}_{2 / 3} \mathrm{MnO}_{3}$ (LCMO) thin films (100nm thick) were grown by Pulsed Laser Deposition on top of commercial platinized silicon. Details of the growth conditions can be found on Ref. [12]. Ti top electrodes consisted in $5 \mu \mathrm{m}$ micropillars embedded in an insulating $\mathrm{SiO}_{2}$ matrix, and were fabricated by a combination of two steps of electronic lithography, reactive ion etching (for the $\mathrm{SiO}_{2}$ ) and electron-beam deposition (for the Ti). The pillars end in rectangular macroscopic pads (suitable for making electrical contact with standard tips) covered by a thin layer of gold, to avoid $\mathrm{Ti}$ oxidation upon exposure to ambient conditions. Figure 1 shows/a sketch with the geometry of the devices in top (a) and cross-section (b) views. Voltage-controlled electrical characterization was performed by using a Keithley 2612 source-meter hooked to a commercial probe station. The Pt bottom electrode was grounded and the stimulus was applied to the top electrode. Virgin resistance values were found in the range $\sim 1-3 \mathrm{M} \Omega$. Figure 1 (c) shows that our devices present bipolar resistive switching upon the application of $1 \mathrm{~ms}$ wide $+2 \mathrm{~V}$ (transition from low to high resistance, RESET process) and $-2.5 \mathrm{~V}$ (transition from high to low resistance, SET process) pulses. The endurance of the device was higher that $\sim 10^{4}$ cycles, and the retentivity of both resistance states was at least 24 hours.

Next, we tested the electrical response of virgin devices by performing pulsed I-V curves and Hysteresis Switching Loops. The pulsed I-V curve is built by applying a sequence of voltage pulses of different amplitude, following the sequence $\left(0 \rightarrow \mathrm{V}_{\mathrm{MAX}} \rightarrow\right.$ $\mathrm{V}_{\text {MIN }} \rightarrow 0$ ), while the current is measured during the application of the pulse. The electrical pulses were $\sim 1 \mathrm{~ms}$ wide and were separated from each other by $\sim 1$ s to avoid self-heating effects. The step in the applied voltage pulses was $10 \mathrm{mV}$ After each of these pulses we apply a small reading voltage of $100 \mathrm{mV}$ that allows measuring the remnant resistance state, in what is called an Hysteresis Switching Loop (HSL).

Figures 2(a) and (b) show consecutive room temperature dynamic I-V curves and HSL obtained by progressively increasing $\mathrm{V}_{\text {MAX }}$ from $2.5 \mathrm{~V}$ to $5 \mathrm{~V}$. Initially, the devices were in a low resistance state (LR) of $\sim 4 \mathrm{M} \Omega$. Upon the application of positive stimulus, the transition to a high resistance state (HR) occurs (RESET process). This transition is gradual and the final $\mathrm{HR}$ state can be tuned by controlling $\mathrm{V}_{\mathrm{MAX}}$, from $30 \mathrm{M} \Omega$ to $100 \mathrm{M} \Omega$ (see Figure 2(d)). The transition from HR to LR (SET process) is obtained with negative stimulus at a voltage $-\mathrm{V}_{\text {SET }}$. A compliance current $\mathrm{CC}=-100 \mu \mathrm{A}$ is set to avoid device damage during the SET process. It is found that $-\mathrm{V}_{\mathrm{SET}}$ increases with the $\mathrm{V}_{\mathrm{MAX}}$ of the previous cycle. We also notice that for this CC, after the SET process the LR state does not return to the value observed in the previous loop. Figure 2(c) corresponds to equivalent HSLs of Figure 2(b), but with the negative compliance current set in a higher value of $-300 \mu \mathrm{A}$. In this case, it is found that after the SET process the previous LR state is recovered. We remark that the virgin resistance value is never recovered, 
indicating that we can identify the first RESET event as a forming process, consistently with the work of Herpers et al. [7]. From the latter description we remark the multilevel capability of our memory devices.

We recall that LCMO is a hole doped manganite and therefore behaves as a type $p$ semiconductor. A thin layer close to the surface is reduced after the deposition of Ti. We refer to this layer as $\mathrm{LCMO}_{3-x}$. The resistivity of this layer increases due to the presence of oxygen vacancies (OV) that disrupts the double exchange Mn-O-Mn bonds [13]. Additionally, the Ti layer close to the $\mathrm{LCMO}_{3-\mathrm{x}}$ is partially oxidized to $\mathrm{TiO}_{\mathrm{x}}$, which behaves as an $n$-type semiconductor where the presence of oxygen vacancies increments its conductivity. Once the external stimulus (voltage) is applied, the OV located at the interface can be drift back and forth between both layers, depending on the polarity of the electrical stimulus. Regarding the LCMO/Pt interface, it behaves as ohmic due to the large work function of Pt $(5.6 \mathrm{eV})$ and therefore we assume that it does not contribute to the resistance changes [14]. The $\mathrm{Ti} / \mathrm{TiO}_{\mathrm{x}}$ interface was also assumed as ohmic, consistently with Ref. [15].

In the following we focus on the $\mathrm{TiO}_{\mathrm{x}} / \mathrm{LCMO}_{3-\mathrm{x}}$ interface to analize SET and RESET processes in terms of $\mathrm{OV}$ transfer. We argue that the initial configuration of $\mathrm{OV}$ in the pristine state (PS) is consistent with a LR state due to the non-stochiometric $\mathrm{TiO}_{\mathrm{x}}$ layer $(\mathrm{x}<2)$ that contributes with a significant conductivity (see the sketch of Fig. 3(b)). The RESET process takes place for positive stimulus and is related to OV (positive ions) transfer from to the $\mathrm{TiO}_{\mathrm{x}}$ layer to the $\mathrm{LCMO}_{3-\mathrm{x}}$ layer, the first becoming nearly stochiometric ( $\mathrm{x} \sim 2$, highly resistive). At the same time, the OV created at the $\mathrm{LCMO}_{3-\mathrm{x}}$ contribute to increase its resistance. As a consequence the HR state is associated to an OV configuration schematized in Fig. 3(b), second panel. Notice that the amount of transferred $\mathrm{OV}$ is controlled by the voltage excursion $\mathrm{V}_{\text {MAX. }}$. The opposite process takes place for negative stimulus and the interface returns to a LR state. However in this case, the amount of OV transferred from the $\mathrm{LCMO}_{3-x}$ to the $\mathrm{TiO}_{x}$ layer is controlled by the $\mathrm{CC}$ triggered at $-\mathrm{V}_{\mathrm{SET}}$ and therefore the final/configuration of $\mathrm{OV}$ for the obtained LR state should not necessarily correspond to the initial one.

To model the described behavior we analyze the dynamics of OV across the $\mathrm{TiO}_{\mathrm{x} /}$ $\mathrm{LCMO}_{3-\mathrm{x}}$ interface. This is the active region for OV migration, that we take as a one dimensional chain of $\mathrm{N}=\mathrm{N}_{L}+\mathrm{N}_{\mathrm{R}}$ sites, with $\mathrm{N}_{\mathrm{L}}$ sites corresponding to the $\mathrm{TiO}_{\mathrm{x}}$ and $\mathrm{N}_{\mathrm{R}}$ sites corresponding to the $\mathrm{LCMO}_{3-\mathrm{x}}$. The links are physically associated to small domains of nanoscopic dimensions in both sub-oxides, with an initial OV concentration associated to the PS. The one dimensional chain, although a simplification of the actual geometry, is in accordance with the experimental evidence indicating that the conduction takes place along a directional path. As the resistivity of the interface is dramatically affected by the precise oxygen stoichiometry, we characterize each site along the chain by its resistivity $\rho_{\mathrm{i}}$, which is a function of the local OV density content $\delta_{\mathrm{i}}$. Following the previous description and taken into account that for $\mathrm{TiO}_{\mathrm{x}}$ the resistivity decreases with the OV content, we define as in Ref [11]

$$
\rho_{i}^{\text {TiOx }}=\frac{\rho_{0}}{1+A_{i} \delta_{i}} \approx \rho_{0}\left(1-A_{i} \delta_{i}\right)
$$

for the local resistivity along the first $\mathrm{N}_{\mathrm{L}}$ sites. On the other hand we take, as in [5], 
for the $\mathrm{N}_{\mathrm{R}}$ sites correspondent to the $\mathrm{LCMO}_{3-\mathrm{x}}$ region. This equation does not take into account the addition of a constant term related to the resistivity of the (undoped) sthoichiometric LCMO, which does not affect the simulations results. The coefficients $\mathrm{A}_{\mathrm{i}}$ 's and $\mathrm{B}_{\mathrm{i}}$ 's are specific of each region/oxide and we take them as constants. We compute the total resistance along the interface as

\section{(3)}

with the proportionality factor taken for simplicity $\mathrm{C} \equiv 1$. The assumed initial oxygen vacancies profile is shown in Figure 3(a) (dashed line) and was chosen consistently with the experimental evidence reported in Ref. [7], and verified also in our samples, that the initial state is a low resistance one. This is related to the Ti layer being partially oxidized to $\mathrm{TiO}_{\mathrm{x}}$ at expenses of a thin LCMO layer reduced to $\mathrm{LCMO}_{3-\mathrm{x}}$. This has been settled by spectroscopic characterization by the Jülich group [7]. Taking into account this initial scenario, the pristine oxygen vacancies density in the $\mathrm{TiO}_{\mathrm{x}}$ should be important enough to increment the conductivity of this layer. Additionally, as the resistivity of the $\mathrm{LCMO}_{3-x}$ increases due to the presence of oxygen vacancies, we need to assume an oxygen vacancies profile in the $\mathrm{LCMO}_{3-\mathrm{x}}$ that does not destroy the $\mathrm{LR}$ initial state of the complete interface. The assumed initial oxygen vacancies profiles match these requirements. Given an external stimulus V(t) (the applied voltage protocol between electrodes), the OV density profile at site $\mathrm{i}$ is updated at each simulation step according to the following rate probability for transferr from site $\mathrm{i}$ to a nearest neighbor $\mathrm{j}$ $=\mathrm{i} \pm 1$, i. e.

, which is proportional to the density of vacancies present at site $i$, and to the available concentration at the neighbor domain $\mathrm{j}$. In the Arrhenius factor, $\exp \left(-\mathrm{V}_{\alpha}+\Delta \mathrm{V}_{\mathrm{i}}\right)$, the local potential drop (or local electric field) at site $i$, is

$$
\Delta V_{i}(t)=V_{i+1}(t)-V_{i}(t)=V(t) \rho_{i} / R
$$

In addition, $\mathrm{V}_{\alpha}$ is the activation energy for vacancy diffusion in the absence of the external applied voltage and in Eq. (4) all the energy scales are taken in units of $\mathrm{k}_{\mathrm{B}} \mathrm{T}$. We consider $\mathrm{V}_{\alpha}=\mathrm{V}_{0}$, for sites in the chain belonging to $\mathrm{TiO}_{\mathrm{x}}$, and $\mathrm{V}_{\alpha}=\mathrm{V}_{1}$ for those sites belonging to the $\mathrm{LCMO}_{3-\mathrm{x}}$. The numerical implementation follows as in Refs [5,11]. We take the following parameters values: $\mathrm{N}=90, \mathrm{~N}_{\mathrm{L}}=50, \mathrm{~N}_{\mathrm{R}}=40, \rho_{0}=5, \mathrm{~A}_{\mathrm{i}}=0.99, \mathrm{~B}_{\mathrm{i}}=2, \mathrm{~V}_{0}$ $=5.6$ and $V_{1}=2.8$. The values chosen for $V_{0}$ and $V_{1}$ are supported by Refs. [16,17], which suggest a larger oxygen vacancies diffusion barrier for $\mathrm{TiO}_{\mathrm{x}}$ (up to $2.5 \mathrm{eV}$ ) with respect to LCMO manganite $(1.3 \mathrm{eV})$.

Figures 4(a) shows the calculated dynamic I-V curves, while Figure 3(b) shows the oxygen vacancies profiles obtained for both HR and LR states after voltage cycling. Despite the similitude with the experimental curves, Figure 4(a) shows that in the simulated I-V, the hysteresis starts immediately after the application of external voltage, indicating the onset of OV migration process. On the contrary, the experimental I-V 
(Figure 2(a)) shows a flat region for low voltage and the hysteresis is triggered after $\sim 0.5 \mathrm{~V}$ for positive stimulus (the hysteresis for negative stimulus is not evident in Figure 2(a) as we stopped the measurements after the CC is triggered during the SET process).

This implies a delay in the onset of OV migration and indicates that an additional ingredient should be taken into account in the modeling. A clue can be obtained from the inset of Figure 4(a), which shows the experimental I-V for low stimuli, below the hysteretic region, resembling the typical shape observed for a Zener diode. This suggests that due to the $n$ and $p$-type character of $\mathrm{TiO}_{\mathrm{x}}$ and $\mathrm{LCMO}_{3-\mathrm{x}}$, respectively, a $n-p$ junction is formed at the interface between both oxides. We stress that for both $\mathrm{Ti} / \mathrm{PCMO} / \mathrm{SRO}$ [7] and Al/PCMO/CMO [18] systems a non-linear current-voltage behavior was reported, but the presence of diodes at $\mathrm{MO}_{\mathrm{x}} /$ manganite ( $\mathrm{M}$ :metal) interfaces was not proposed in any case. To cope with this electronic effect in the I-V simulation, we now consider that the total voltage $\mathrm{V}$ along the sample is dropped as

, where $\Delta \mathrm{V}_{\mathrm{R}(\mathrm{OV})}$ accounts for the (resistive) voltage drop related to the redistribution of OV (Eqs. (1)-(3)) and $\Delta V_{D}$ for the electronic effect at the interface and linked to the current $I$ through the Shockley equation [19]. By taken this modification into account, we replace in Eq.(6) and obtain the simulated $\mathrm{I}-\mathrm{V}$ curve shown in Figure 4(b), which now matches nicely the experimental one. The calculated HSLs are shown in Figure 4(c) (main panel and insêt) for different negative voltage excursions (corresponding to different CCs in the experimental counterparts), which display shapes that resemble the experimental loops (Figure 2). It can be stated that the OV migration is only activated after the diode is forwardly polarized (positive voltage) or inversely polarized above breakdown (negative voltage). Further information about the diode can be obtained from Figure 4(d), which shows I-V curves at different temperatures measured in the negative quadrant. It is found that the breakdown voltage $\mathrm{V}_{\mathrm{b}}$ (which is concomitant with the HR $\rightarrow \mathrm{LR}$ transition) decreases as the temperature is increased, at a rate of $-2 \mathrm{mV} / \mathrm{K}$. The evolution of $\mathrm{V}_{\mathrm{b}} \mathrm{Vs}$. $\mathrm{T}$ is depicted in the inset of Figure 5. The observed behavior is consistent with a low-breakdownvoltage Zener diode, characteristic of highly doped $p$ - $n$ junctions with a thin depletion layer [20].

Finally, we point out that the $\mathrm{TiO}_{x}$ layer displays the dominant contribution to the overall resistance of our devices. We estimated the contribution of both $\mathrm{TiO}_{\mathrm{x}}$ and $\mathrm{La}_{0.33} \mathrm{Ca}_{0.67} \mathrm{MnO}_{3-\mathrm{x}}$ layers from Eq. (3) for the pristine (PR), HR and LR states, finding that the $\mathrm{TiO}_{\mathrm{x}}$ layer displays average values of $0.1,1.4$ and 0.32 a.u./site, respectively, while the corresponding values for the $\mathrm{La}_{1 / 3} \mathrm{Ca}_{2 / 3} \mathrm{MnO}_{3 \text {-x }}$ layer are $0.02,0.66$ and 0.13 a.u./site, respectively. A similar scenario is proposed for $\mathrm{TiO}_{\mathrm{x}}$ in $\mathrm{Ti} / \mathrm{TiO}_{\mathrm{x}} / \mathrm{PCMO}$ [7] and $\mathrm{AlO}_{\mathrm{x}}$ in $\mathrm{Al} / \mathrm{AlO} \mathrm{x} / \mathrm{LSMO}$ [21]. We notice that if we modify the simulation parameters to allow the $\mathrm{LCMO}_{3-\mathrm{x}}$ layer to dominate the resistance of the device, the calculated HSLs do not mimic the experimental ones (not shown here), reinforcing the consistency of our modeling. In relation to the bulk LCMO contribution to the resistance, it is well established that this zone presents a substantial lower resistance than the interfacial $\mathrm{LCMO}_{3-\mathrm{x}}$ zone, due to the presence of interfacial potential barriers [5]. From this analysis, we can conclude that the contributions to the overall resistance of $\mathrm{TiO}_{\mathrm{x}}$, interfacial $\mathrm{LCMO}_{3-\mathrm{x}}$ and bulk LCMO layers order according to $\mathrm{R}_{\mathrm{TiOx}}>\mathrm{R}_{\mathrm{LCMO}-}$ $\mathrm{x}>>\mathrm{R}_{\mathrm{LCMO}}$. 
In summary we have fabricated memristive microdevices in which the RS is associated to a redox process at the $\mathrm{TiO}_{\mathrm{x}} / \mathrm{La}_{1 / 3} \mathrm{Ca}_{2 / 3} \mathrm{MnO}_{3-\mathrm{x}}$ interface. We have demonstrated the existence of multilevel states by controlling the voltage excursion during the RESET process. This multilevel capability turns our devices interesting for the development of high density RRAM devices. By adapting the VEOV model we successfully reproduced the experimental electrical behavior, after the inclusion of a Zener-type diode at the $\mathrm{TiO}_{\mathrm{x}} / \mathrm{LCMO}_{3-\mathrm{x}}$ interface. Our analysis indicates that oxygen vacancies migration between both layers is activated after the diode is polarized either in forward mode or in reverse mode above breakdown. Our work shows that a combined rectifying ( $\mathrm{p}-\mathrm{n}$ diode) and memristive behavior can be found at a single interface $\left(\mathrm{LCMO}_{3-\mathrm{x}} / \mathrm{TiO}_{\mathrm{x}}\right)$, suggesting an avenue for the development of $1 \mathrm{~S} 1 \mathrm{R}$ crossbar arrays where the selecting and memristive functionalities are linked to the same interface, simplifying the device fabrication procedure. We estimated for our devices a nonlinearity factor $\alpha=$ $\frac{R_{L R S} @ V_{\text {read }} / 2}{R_{L R S} @ V_{\text {read }}} \sim 10$ for $V_{\text {read }}=0.8 \mathrm{~V}$. From the obtained $\alpha$, and following the work of Huang et al. [22], a 1S1R crossbar array density of some kbits can be roughly estimated for our devices. This density is lower than the 10Mbits estimated for the high performance $\mathrm{Ni} / \mathrm{TiO}_{2} / \mathrm{Ni} / \mathrm{HfO}_{2} / \mathrm{Pt}$ stacks reported by Huang et al., where, unlike our case, different selecting and memristive elements were stacked $\left(\mathrm{Ni} / \mathrm{TiO}_{2} / \mathrm{Ni}\right.$ and $\mathrm{Ni} / \mathrm{HfO}_{2} / \mathrm{Pt}$, respectively) [22]. However, as the physical mechanisms reported here for $\mathrm{LCMO} / \mathrm{TiO}_{\mathrm{x}}$ can be expected for other p-type oxide/TiO ${ }_{\mathrm{x}}$ interfaces (including CMOS compatible p-type oxides), we understand there is room for materials optimization and engineering in order to significantly increase the diode nonlinearity factor and therefore the crossbar array density.

We acknowledge financial support from ANPCyT (projects PICT 0788-2013, PICT 2116-2014 and PICT 1382-2014). CONICET (project PIP 11220150100218), U. N. Cuyo (project 06/C455) and NanoPymes MINCyT program. We thank U. Lüders and J. Lecourt, from CRISMAT, for the preparation of the manganite target, and L. Hueso, from nanoGUNE, for the access to their nanofabrication facilities.

\section{$\underline{\text { Figure captions }}$}

Figure 1: Sketches showing the device geometry for both cross-section (a) and top view (b); (c) Bipolar resistive switching upon the application of +2V (RESET process) and $2.5 \mathrm{~V}$ (SET process) pulses. Endurance was found higher that $10^{4}$ events. The inset shows the corresponding histograms for each resistance level.

Figure 2: (a) Experimental/consecutive I-V curves recorded for a $5 \mu \mathrm{m}$ device, obtained by progressively increasing the positive voltage excursion $\mathrm{V}_{\mathrm{MAX}}$ from $2.5 \mathrm{~V}$ to $5 \mathrm{~V}$; (b) Hysteresis switching loops recorded simultaneously to the I-V curves displayed in (a), with a SET CC=-100 $\mu \mathrm{A}$; (c) Hysteresis switching loops obtained after increasing the SET CC to $-300 \mu \mathrm{A}$; (d) Evolution of the (remanent) HR state for different VMAX.

Figure 3: (a) Oxygen vacancies profiles assumed for the pristine state (black dashed line) and obtained after running the simulations for HR (red line) and LR (green line) 
states; (b) Sketch showing the oxygen vacancies distributions for both $\mathrm{TiO}_{\mathrm{x}}$ and $\mathrm{LCMO}_{3-\mathrm{x}}$ layers for pristine, HR and LR states.

Figure 4: (a),(b) Simulated I-V curves for different voltage excursions by using the VEOV drift model, before and after including the electronic effect at the $\mathrm{TiO}_{\mathrm{x}} / \mathrm{LCMO}_{3-\mathrm{x}}$ interface; (c) The main panel shows the simulated HSLs associated to Fig. 4(b). The inset displays HSLs for a higher voltage excursion that emulates a higher experimental CC; (d) Experimental I-V curves at different temperatures measured in the negative quadrant. The inset displays the evolution of the breakdown voltage $\mathrm{V}_{\mathrm{b}}$ with $\mathrm{T}$. 
$\underline{\text { References }}$

[1] A. Sawa, Mater. Today 11, 28 (2008).

[2] R. Waser, R. Dittmann, G. Staikov and K. Szot, Adv. Mater. 21, 2632 (2009).

[3] S.Q. Liu, N. J. Wu, and A. Ignatiev, Appl. Phys. Lett. 76, 2749 (2000).

[4] M.J. Rozenberg, I.H. Inoue and M.J. Sánchez; Phys. Rev. Lett.. 92, 178302 (2004).

[5] M. J. Rozenberg, M. J. Sánchez, R. Weht, C. Acha, F. Gomez-Marlasca, and P. Levy, Phys. Rev. B 81, 115101 (2010).

[6] D. Rubi, F. Tesler, I. Alposta, A. Kalstein, N. Ghenzi, F. Gomez-Marlasca, M. Rozenberg, and P. Levy, App. Phys. Lett. 103, 163506 (2013).

[7] A. Herpers, C. Lenser, C. Park, F. Offi, F. Borgatti, G. Panaccione, S. Menzel, R. Waser and R. Dittmann, Adv. Mat. 26, 2730 (2014).

[8] S. Asanuma et al., Phys. Rev. B 80, 235113 (2009)

[9] B. Tian, P. Nukala, M.B. Hassine, X. Zhao, X. Wang, H. Shen, J. Wang, S. Sun, T. Lin, J. Sun, J. Ge, R. Huang, C. Duan, T. Reiss, M. Varela, B. Dkhil, X. Meng and J, Chu, Phys. Chem. Chem. Phys. 19, 16960 (2017)

[10] W. Román Acevedo et al. Appl. Phys. Lett. 110, 053501 (2017)

[11] N. Ghenzi et al., J. Phys. D: Appl. Phys. 46, 415101(2013).

[12] E. Miranda et al., J. Appl. Phys. 121, 205302 (2017).

[13] A. Asamitsu et al. Nature 388, 50 (1997).

[14] A. Herpers, Electrical characterization of manganite and titanate structures, $\mathrm{PhD}$ Thesis, Forschungszentrum Jülich (2014)

[15] F. Hossein-Babaei and S.Rahbarpour, Solid-State Electronics 56, 185 (2011)

[16] Wang et al Phys. Rev. B 82, 165309 (2010)

[17] B. Vengalis et al., J. Phys. IV France 11, PR11-209 (2001)

[18] Hong-Sub Lee, Hyung-Ho Park and M. J. Rozenberg, Nanoscale 7, 6444 (2015)

[19] S.M. Sze and K.K. Ng, Physics of Semiconductor Devices, Wiley, New Jersey (2007).

[20] M. Singh Tyagi, Solid-State Electronics, 11, 117 (1968)

[21] N. Lee, Y.B. Lansac, H.C. Hwang, and Y.H. Jang, RSC Adv. 5, 102772 (2015)

[22] Huang et al., Electron Devices Meeting (IEDM), 2011, DOI: 10.1109/IEDM.2011.6131653 

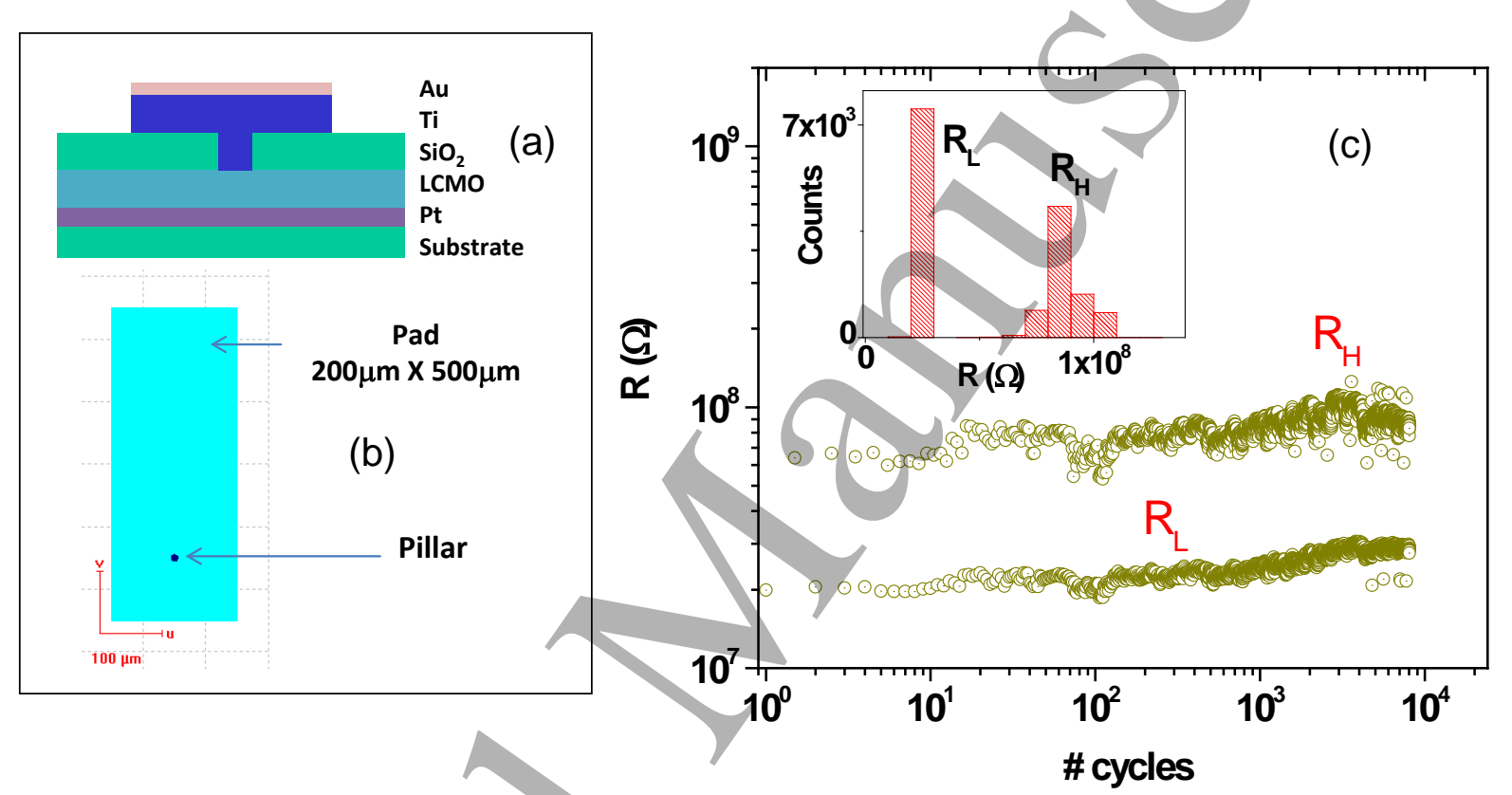

FIGURE 1 

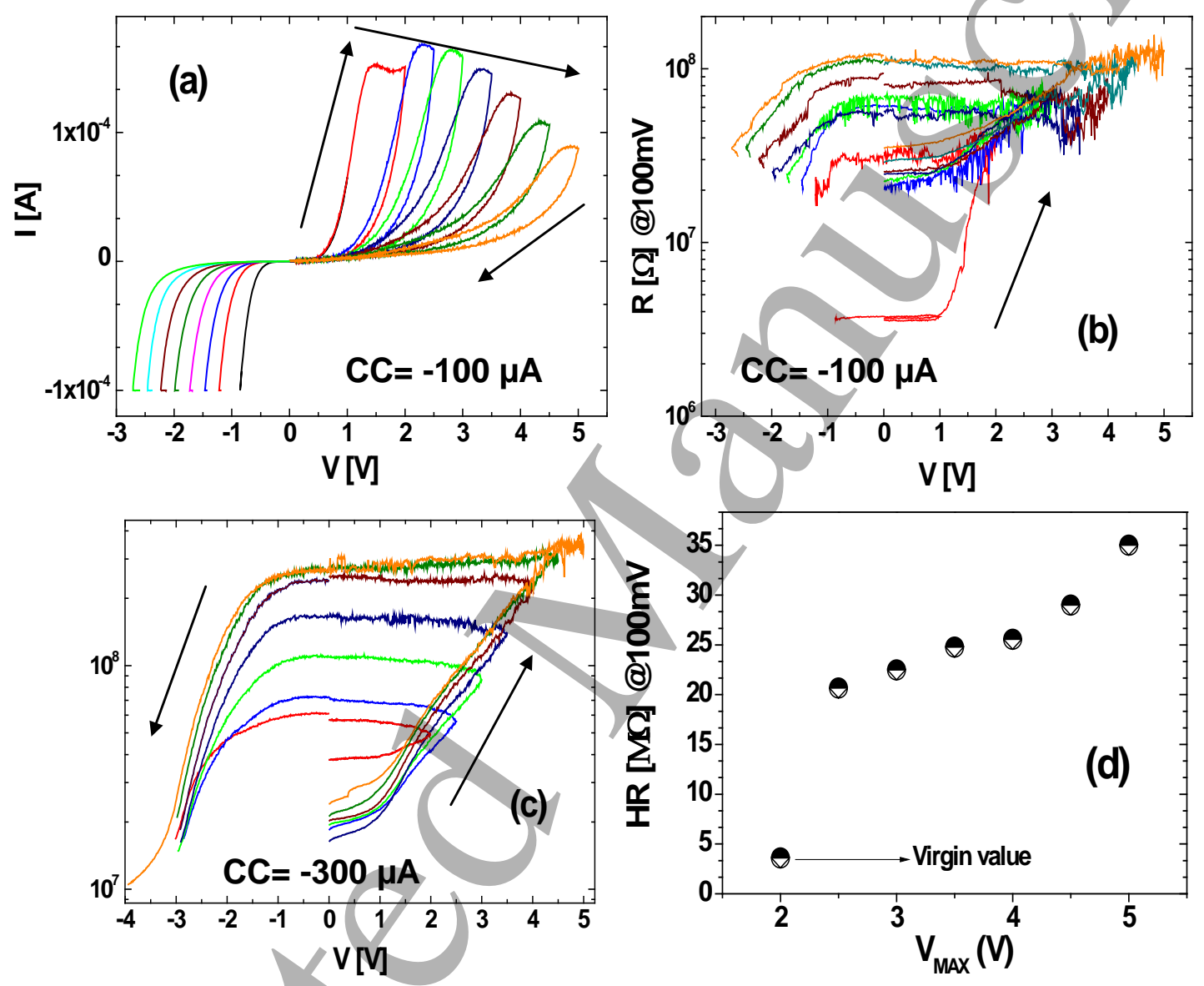

FIGURE 2 


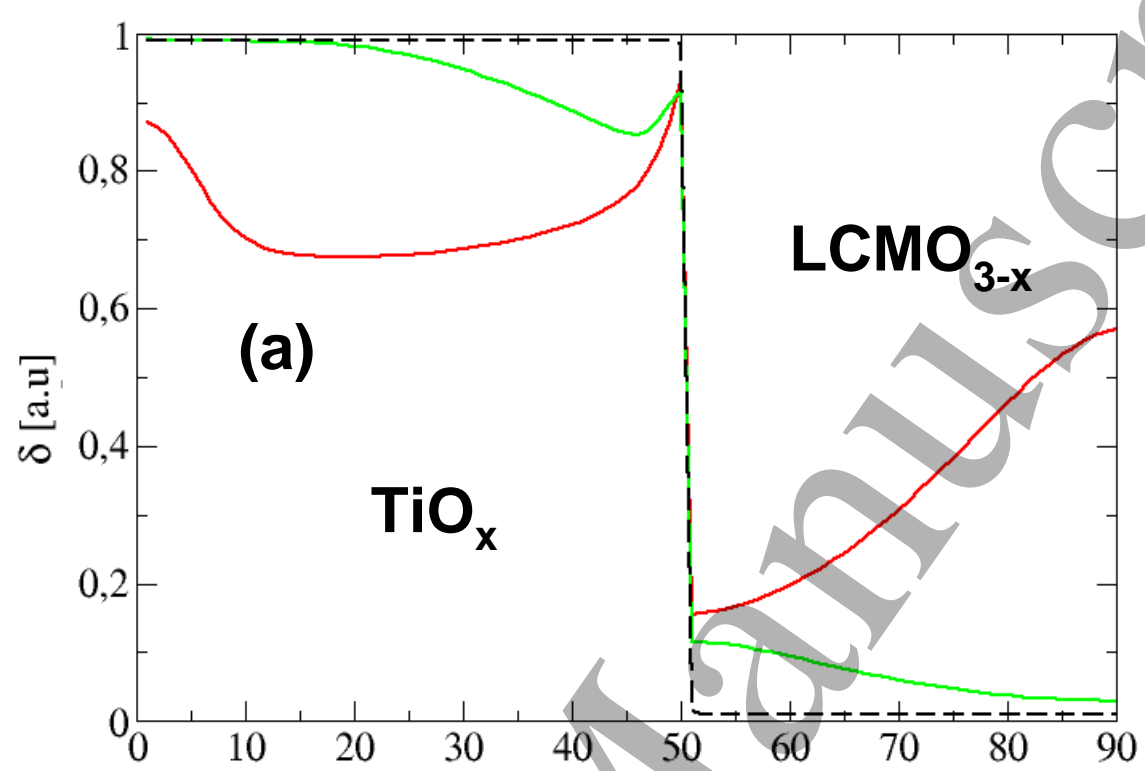

\# Site

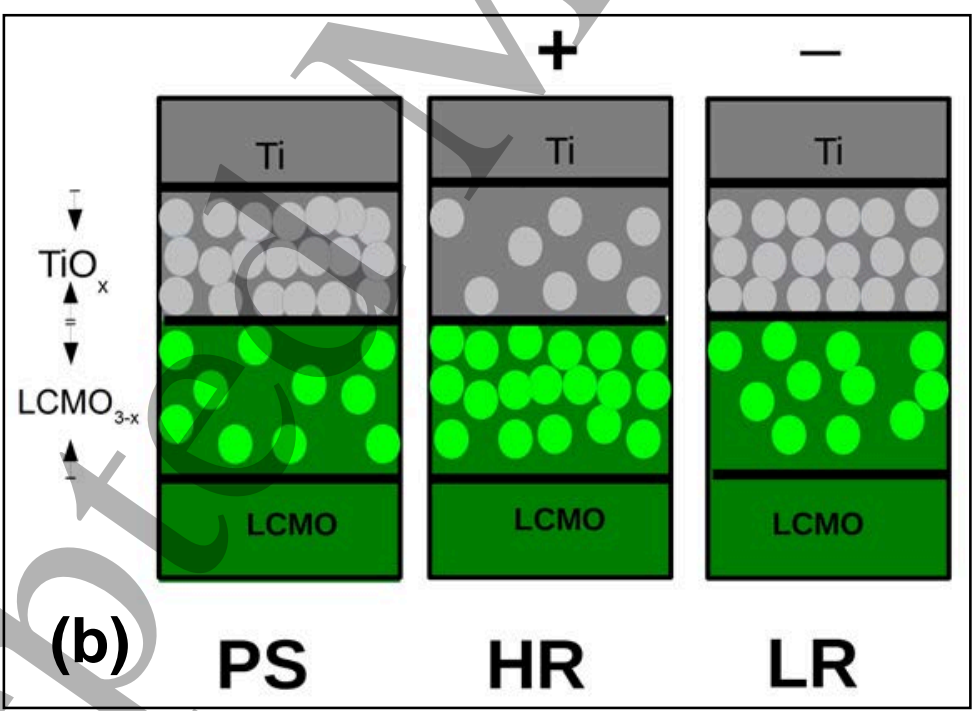

FIGURE 3 

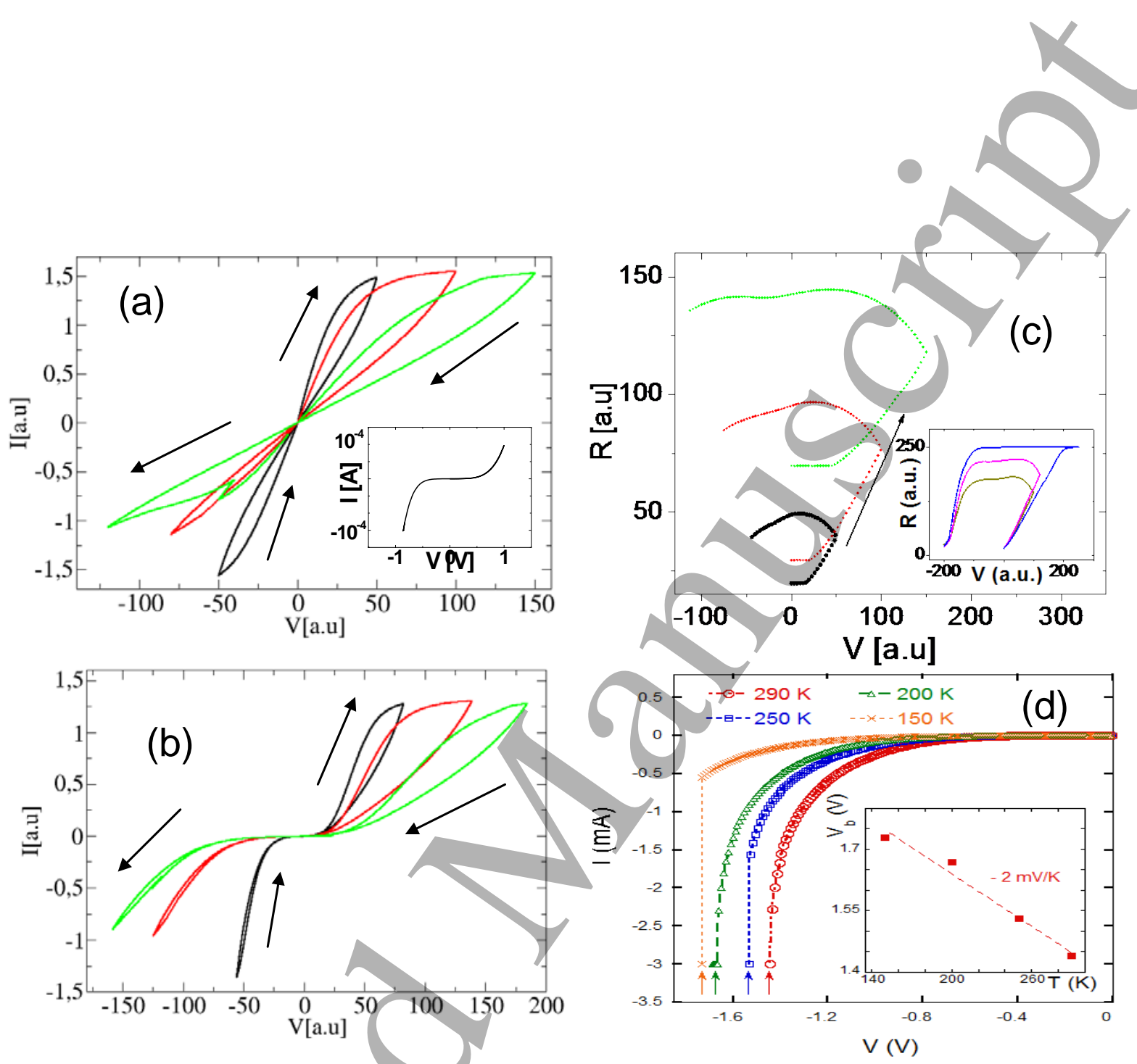

FIGURE 4 